\title{
Cyclin D1 immunoreactivity in normal endocervix and diagnostic value in reactive and neoplastic endocervical lesions
}

\author{
Leonie Little and Colin John Reid Stewart \\ Department of Histopathology, King Edward Memorial Hospital, Perth, Western Australia, Australia
}

\begin{abstract}
It may be difficult to distinguish reactive glandular lesions from adenocarcinoma in situ of the uterine cervix, and although several immunohistochemical markers have established value in this diagnostic setting, none is completely reliable. We have noted that neoplastic endocervical lesions often show loss of nuclear cyclin D1 expression in contrast to benign glandular cells. Therefore, we investigated cyclin D1 staining in a series of 64 cervical biopsy specimens including examples of normal and reactive endocervical epithelium, adenocarcinoma in situ, stratified mucin-producing intraepithelial lesions, and invasive adenocarcinoma. Thirteen specimens also included a component of high-grade cervical squamous intraepithelial neoplasia. Normal endocervical epithelium usually expressed cyclin D1, although staining was typically focal, and there was increased immunoreactivity in reactive and metaplastic glandular cells including tubo-endometrioid metaplasia. In contrast, most cases of adenocarcinoma in situ were completely negative and, therefore, cyclin D1 staining distinguished benign from neoplastic epithelial cells. Although focal cyclin D1 expression was observed in 5/19 cases of adenocarcinoma in situ, the staining was associated with more marked cytological atypia precluding confusion with a reactive process. The invasive adenocarcinomas were mainly negative for cyclin D1. However, focal staining was observed in 10/19 cases and was mainly restricted to cells at the deep tumor margin, or to small infiltrative glands and detached cell clusters within the stroma. In conclusion, cyclin D1 can be included within an immunohistochemical panel to aid in the distinction between reactive cervical glandular lesions and adenocarcinoma in situ. The localized distribution of staining within invasive lesions suggests that cyclin D1 up-regulation has a specific role during the progression of some endocervical adenocarcinomas.
\end{abstract}

Modern Pathology (2010) 23, 611-618; doi:10.1038/modpathol.2009.178; published online 8 January 2010

Keywords: cervix; adenocarcinoma; cyclin D1; invasion; immunohistochemistry

Adenocarcinoma of the cervix is increasing in incidence in many countries and now accounts for up to $25 \%$ of all cervical carcinomas. ${ }^{1,2}$ The reasons for this increase are not completely clear although it is accepted that cervical screening is less effective at detecting adenocarcinoma and its precursor adenocarcinoma in situ, also termed cervical glandular intraepithelial neoplasia. ${ }^{3}$ The diagnosis of adenocarcinoma in situ in cytological or punch biopsy specimens has important clinical implications as

Correspondence: Dr CJR Stewart, FRCPA, Department of Histopathology, King Edward Memorial Hospital, Bagot Road, Subiaco, Perth, Western Australia 6008, Australia.

E-mail: colin.stewart@health.wa.gov.au

Received 2 October 2009; revised 2 December 2009; accepted 7

December 2009; published online 8 January 2010 these lesions are usually treated by cone biopsy of the cervix, a relatively aggressive diagnostic and therapeutic procedure that may have fertility implications in younger patients. Moreover, as it is acknowledged that the cytological follow-up of adenocarcinoma in situ can be problematic, ultimately patients may be advised to undergo hysterectomy. ${ }^{1,4}$

The histological diagnosis of adenocarcinoma in situ is straightforward in most cases and the morphological features are well described. ${ }^{5}$ However, glandular lesions of the cervix may present a number of diagnostic difficulties to histopathologists including in some instances the distinction of adenocarcinoma in situ from benign mimics including tubal or tubo-endometrioid metaplasia. ${ }^{6,7}$ Therefore, immunohistochemical stains that aid in this 
differential diagnosis are often used in problematic cases and among the most widely used markers are p16 ${ }^{\mathrm{INK} 4 \mathrm{~A}}$ (hereafter referred to as p16) protein, Ki-67/ MIB-1, and bcl-2. ${ }^{8,9}$ Generally, adenocarcinoma in situ is negative for bcl-2 but shows diffuse/increased labeling of p16 protein and Ki-67, whereas reactive glandular lesions typically show the converse staining pattern. However, although these antibodies are extremely helpful, none is completely reliable in an individual case. Furthermore, the characteristic staining patterns (focal versus diffuse) may be difficult to assess in small samples such as punch biopsies, or when minimal lesional tissue is included in the specimen. Therefore, additional reliable immunohistochemical markers might be helpful in problematic cases.

Cyclin D1 is critical to the initiation of cellular proliferation in normal cells where it promotes progression through the G1-S phase of the cell cycle. ${ }^{10-12}$ Cyclin D1 associates with the cyclindependent kinases (CDKs), mainly CDK4 or CDK6, to form a complex that phosphorylates and hence inhibits the function of the retinoblastoma (RB) protein. In turn, loss of RB protein activity induces cells to enter $S$ phase and thereafter progress through the cell cycle. Many additional factors exert positive or negative effects on the control of cellular proliferation including p16 protein, which functions as a CDK inhibitor and thus antagonizes the actions of the cyclin D1-CDK complex. ${ }^{13}$ Self-regulatory feedback loops also exist between these mediators so that active RB protein stimulates the up-regulation of cyclin D1 but leads to reduced expression of p16 protein. Many tumors exhibit abnormalities within the RB-p16-cyclin D1 pathways, and often these lead to increased activity of cyclin D1. ${ }^{10-12}$ However, we have noted in routine practice that adenocarcinoma in situ and invasive cervical adenocarcinoma usually lack expression of cyclin D1, whereas the nuclei of most normal endocervical epithelial cells are positively stained. This seems a surprising finding as neoplastic endocervical lesions are typically characterized by prominent mitotic activity and show increased expression of the proliferationassociated marker Ki-67/MIB-1. Relatively few studies have investigated cyclin D1 expression within the normal cervix or in cervical neoplasia, and most of the latter have focused on the more common in situ and invasive squamous lesions. To our knowledge, none has evaluated cyclin D1 immunohistochemistry in reactive or metaplastic endocervical lesions, or assessed its potential role in the diagnosis of problematic cervical biopsies. Therefore, we have examined cyclin D1 expression in a series of cervical specimens including cases of normal cervical epithelium, tubo-endometrioid metaplasia, adenocarcinoma in situ and invasive adenocarcinoma, and have compared the findings with three other immunohistochemical markers, p16, Ki-67, and bcl-2, that are commonly used in diagnostically challenging cases.

\section{Materials and methods}

Sixty-four cervical histopathology specimens obtained from loop excisions of the transformation zone, scalpel cone biopsies, or hysterectomy specimens were identified within the files of the Histopathology Department, King Edward Memorial Hospital, Perth. All tissues were fixed in neutralbuffered formalin and routinely processed to paraffin wax. There were 19 cases of conventional adenocarcinoma in situ, 7 cases of stratified mucin-producing intraepithelial lesion, ${ }^{14}$ and 19 invasive endocervical adenocarcinomas. All invasive tumors were of 'usual' endocervical type ${ }^{15}$ and only 1 case exhibited prominent extra-cellular mucin production; 17 invasive tumors were moderately differentiated and 2 were poorly differentiated. There were also 23 examples of tubo-endometrioid metaplasia, four of which were included in specimens predominantly showing adenocarcinoma in situ. Three of the tubo-endometrioid metaplasia specimens were associated with a focal endometrioid-type stromal alteration (stromal endometriosis). All seven biopsies exhibiting stratified mucinproducing intraepithelial lesions and six of the 19 conventional adenocarcinoma in situ specimens also included foci of high-grade squamous intraepithelial neoplasia (CIN 2 or CIN 3), and one of these cases showed focal microinvasive squamous carcinoma that extended $<1 \mathrm{~mm}$ in depth and lateral extent. Histologically normal endocervical epithelium was included for assessment in 47 of the specimens (18 with tubo-endometrioid metaplasia, 18 with adenocarcinoma in situ, 7 with stratified mucin-producing intraepithelial lesion, and 4 with adenocarcinoma), whereas normal squamous epithelium was present in 50 cases (15 with tuboendometrioid metaplasia, 17 with adenocarcinoma in situ, 7 with stratified mucin-producing intraepithelial lesion, and 11 with adenocarcinoma). Although the following were not addressed in detail in this study, the pattern of staining in foci of reserve cell hyperplasia/immature squamous metaplasia and in endocervical microglandular hyperplasia was noted where present. Two specimens also included incidental mesonephric duct remnants.

One selected block from each case was stained immunohistochemically for cyclin D1, p16 protein, Ki-67, and bcl-2 using an auto-immunostainer (Ventana Medical Systems, Benchmark XT) according to the manufacturer's instructions. A summary of the primary antibodies and the immunohistochemical technique is provided in Table 1. The proportion of immunoreactive cells with each antibody was categorized as negative, focally positive $(<50 \%$ cells stained), or diffusely positive $(>50 \%$ cells stained). However, care was taken to identify consistent microanatomical patterns of staining even if these involved only a minority of cells overall. 


\section{Results}

The immunohistochemical findings are summarized in Table 2. There was no apparent difference in the staining patterns of the normal squamous or endocervical epithelia according to the concurrent histological findings (tubo-endometrioid metaplasia, adenocarcinoma in situ, stratified mucinproducing intraepithelial lesion, or invasive adenocarcinoma), nor did the immunoreactivity of the adenocarcinoma in situ and stratified mucin-producing intraepithelial lesions differ according to the presence of concurrent CIN.

Normal mature squamous epithelium showed consistent bcl-2 expression within basal cells, whereas cyclin D1 and Ki-67 mainly labeled parabasal cells (Figure 1). There was no expression of p16 protein. However, immature squamous metaplasia and squamous epithelium showing inflammatory and reactive changes sometimes showed focal p16 expression and more prominent cyclin D1 and Ki-67 immunoreactivity (Figure 2).

High-grade CIN generally did not express bcl-2 or cyclin D1 although focal $(<5 \%)$ labeling of parabasal cells was seen with the latter antibody in 2/13 cases. In addition, the single case that included a small focus of superficially invasive squamous carcinoma showed cyclin D1 expression within the invasive component contrasting with the adjacent unstained CIN 3. As expected, the CIN showed diffuse nuclear and cytoplasmic p16 protein expression accompanied by markedly increased Ki-67 labeling that extended through all cell layers. The stratified mucin-producing intraepithelial lesions

Table 1 Summary of immunohistochemical methods

\begin{tabular}{lllll}
\hline Antibody & Source & Clone & Dilution & Antigen retrieval \\
\hline p16 & Santa Cruz & JC-8 & $1 / 200$ & Mild (30 min) \\
Ki67 & Dako & MIB-1 & $1 / 150$ & Extended (90 min) \\
Bcl-2 & Dako & 12Y & $1 / 40$ & Standard (60 min) \\
Cyclin D1 & Neomarkers & SP4 & $1 / 50$ & Mild (30 min) \\
\hline
\end{tabular}

showed a similar immunoprofile to that of CIN except that p16 protein expression was less prominent, possibly because the cytoplasm predominantly comprised unstained mucin vacuoles.

The nuclei of normal endocervical cells were positive for cyclin D1 in most specimens and only three cases were completely unstained (Figure 1). Although immunoreactivity was typically focal, it was unusual for normal glands or crypts to be entirely cyclin D1 negative. Staining was also increased in reactive endocervical cells notably in the presence of concurrent inflammation (Figure 2). Normal endocervical cells were bcl-2 negative and only rare isolated cells showed Ki-67 or p16 protein expression. However, Ki-67 and p16 labeling was increased in reactive settings such as endocervicitis.

Tubo-endometrioid metaplasia was typically cyclin D1 positive, with staining in $\sim 50 \%$ of cells in most cases (Figure 3). There was bcl-2 immunoreactivity in all except one case of tubo-endometrioid metaplasia but the epithelial staining was often weak in comparison to the adjacent lymphoid cells. The majority of tubo-endometrioid metaplasia cases showed expression of p16 protein and focal Ki-67 labeling. Staining with p16 was focal in most cases, and sometimes limited to single cells in otherwise negative glands, but eight cases included glands that were diffusely p16 positive and/or showed Ki-67 labeling in $>25 \%$ of cells. Only three cases of microglandular hyperplasia were included but all showed diffuse cyclin D1 staining (Figure 3). The mesonephric duct remnants showed expression of all antibodies tested but $<10 \%$ cells expressed cyclin D1, Ki-67, and p16 protein.

All cases of adenocarcinoma in situ showed markedly increased Ki-67 labeling together with diffuse nuclear and cytoplasmic reactivity for p16 protein. Typically, the positive cells were sharply demarcated from the adjacent normal, unstained endocervical epithelium. In contrast, adenocarcinoma in situ usually was completely negative for cyclin D1 and, therefore, the loss of staining demarcated the neoplastic glands from the adjacent

Table 2 Summary of main staining patterns with each antibody in normal, reactive, and neoplastic cervical epithelium

\begin{tabular}{|c|c|c|c|c|}
\hline & Cyclin D1 & p16 & $K i-67$ & $B c l-2$ \\
\hline Benign squamous epithelium & $\begin{array}{l}\text { Parabasal cells (increased } \\
\text { in reactive) }\end{array}$ & $\begin{array}{l}\text { Negative (focal staining in } \\
\text { reactive cells) }\end{array}$ & $\begin{array}{l}\text { Parabasal cells (increased } \\
\text { in reactive) }\end{array}$ & Basal cells \\
\hline $\begin{array}{l}\text { High grade CIN/stratified mucin- } \\
\text { producing intraepithelial lesion }\end{array}$ & $\begin{array}{l}\text { Negative (focal staining } \\
\text { of parabasal cells) }\end{array}$ & Diffusely positive & Increased in all cell layers & Negative \\
\hline Normal endocervical epithelium & $\begin{array}{l}\text { Positive, usually focal } \\
\text { (increased in reactive) }\end{array}$ & $\begin{array}{l}\text { Negative (rare single cells } \\
\text { positive) }\end{array}$ & $\begin{array}{l}\text { Negative (rare single cells } \\
\text { positive) }\end{array}$ & Negative \\
\hline Tubo-endometrioid metaplasia & Positive, usually focal & $\begin{array}{l}\text { Positive, usually focal } \\
\text { (occasionally diffuse) }\end{array}$ & $\begin{array}{l}\text { Variable, usually focally } \\
\text { positive }\end{array}$ & $\begin{array}{l}\text { Positive } \\
\text { (sometimes } \\
\text { weak/focal) }\end{array}$ \\
\hline Adenocarcinoma in situ & $\begin{array}{l}\text { Negative }(<10 \% \text { staining } \\
\text { in } 5 \text { cases })\end{array}$ & Diffusely positive & Diffusely increased & Negative \\
\hline Invasive adenocarcinoma & $\begin{array}{l}\text { Negative (focal staining } \\
\text { mainly at deep margin) }\end{array}$ & Diffusely positive & Diffusely increased & Negative \\
\hline
\end{tabular}



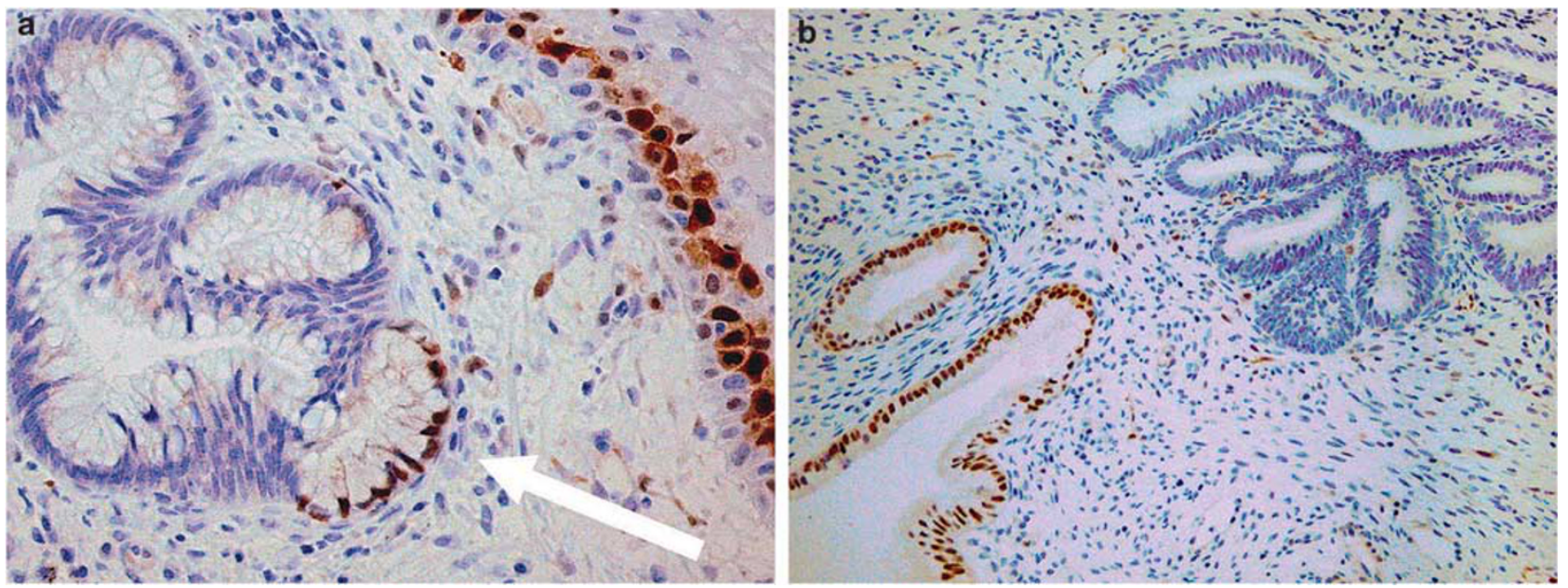

Figure 1 (a) Cyclin D1 staining is present within the parabasal cells of normal squamous epithelium (right) and in normal endocervical cells (arrow), whereas adenocarcinoma in situ is not stained. (b) There is cyclin D1 expression within normal endocervical crypts (lower left field) and in occasional stromal cells, whereas the glands showing adenocarcinoma in situ (upper right field) are negative.
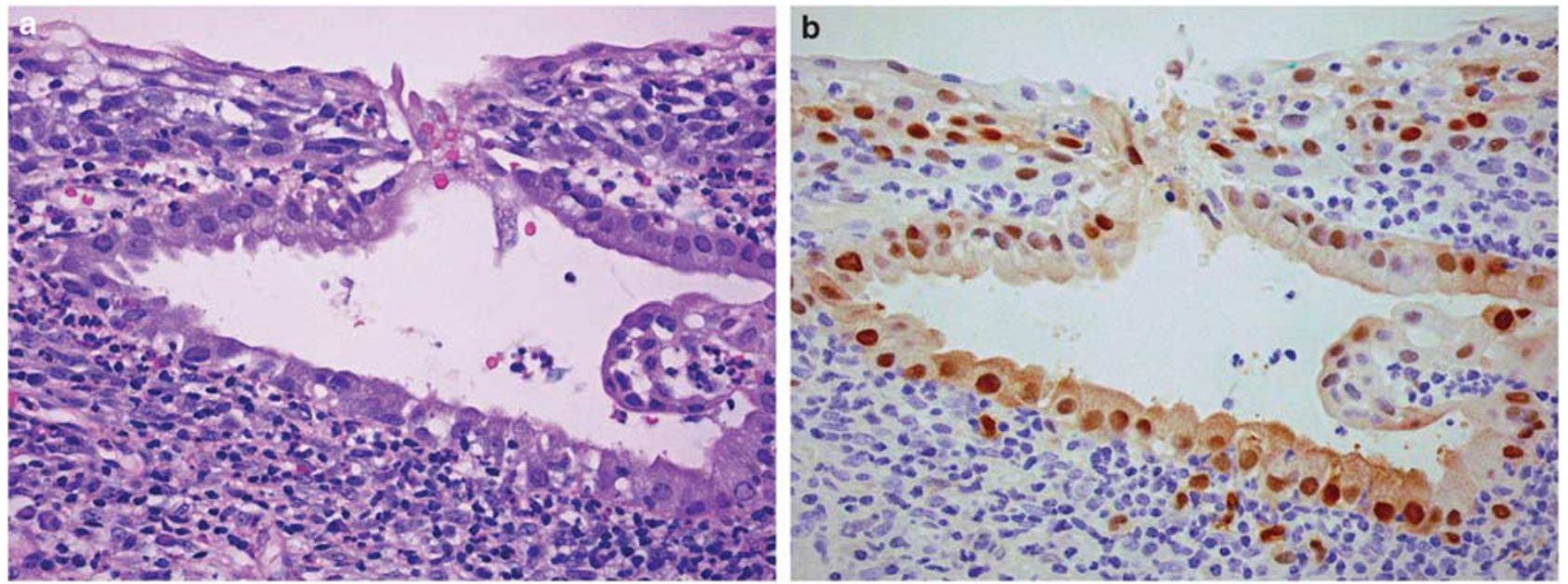

Figure 2 (a and b) Cervicitis is associated with increased nuclear cyclin D1 expression in reactive glandular and squamous epithelium. Note that some cells also show cytoplasmic immunoreactivity.
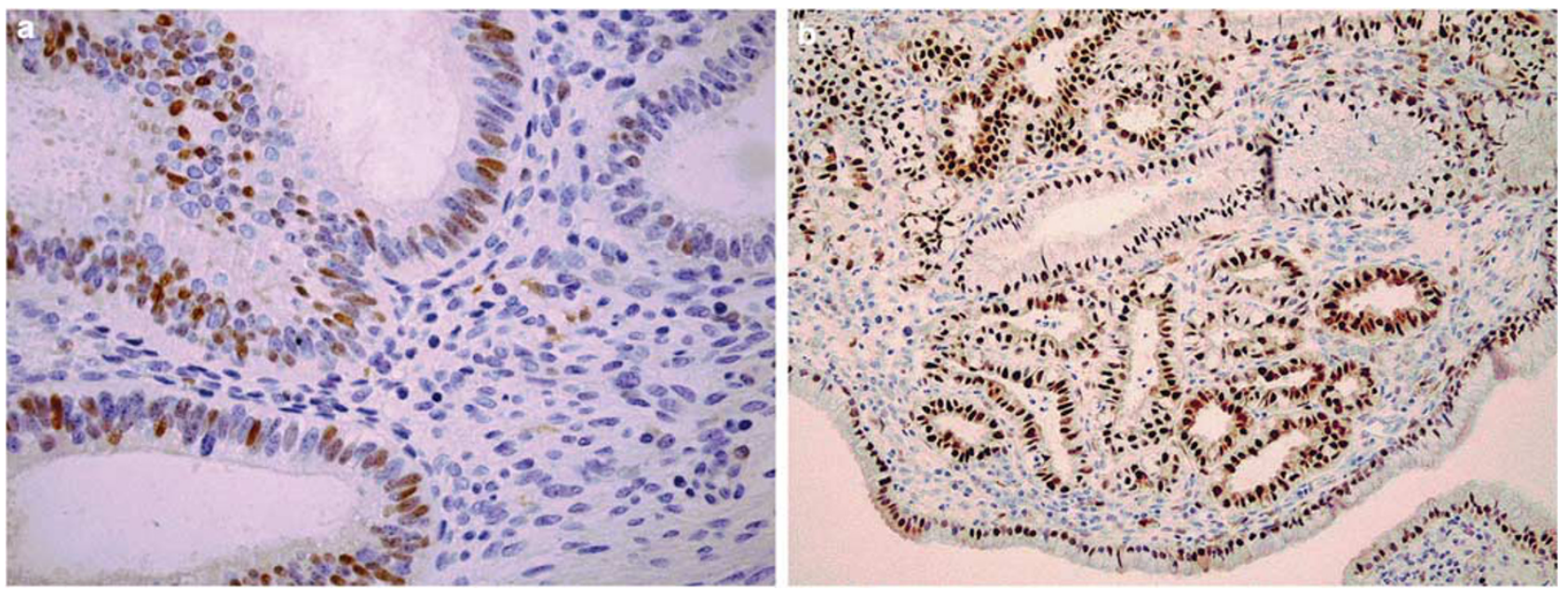

Figure 3 Tubo-endometrioid metaplasia (a) and microglandular hyperplasia (b) show nuclear cyclin D1 expression. 

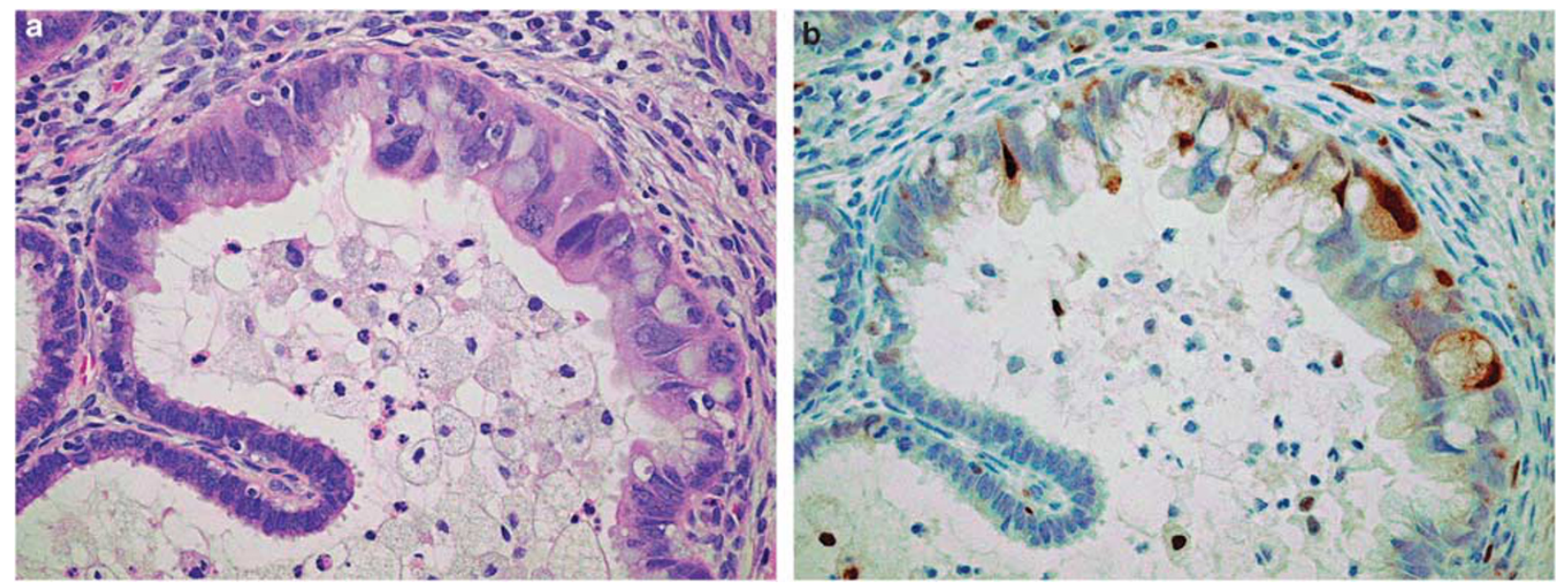

Figure 4 (a and b) Cyclin D1 expression within adenocarcinoma in situ is localized to an area in which there is more marked cytological atypia. Some cells show both nuclear and cytoplasmic staining.
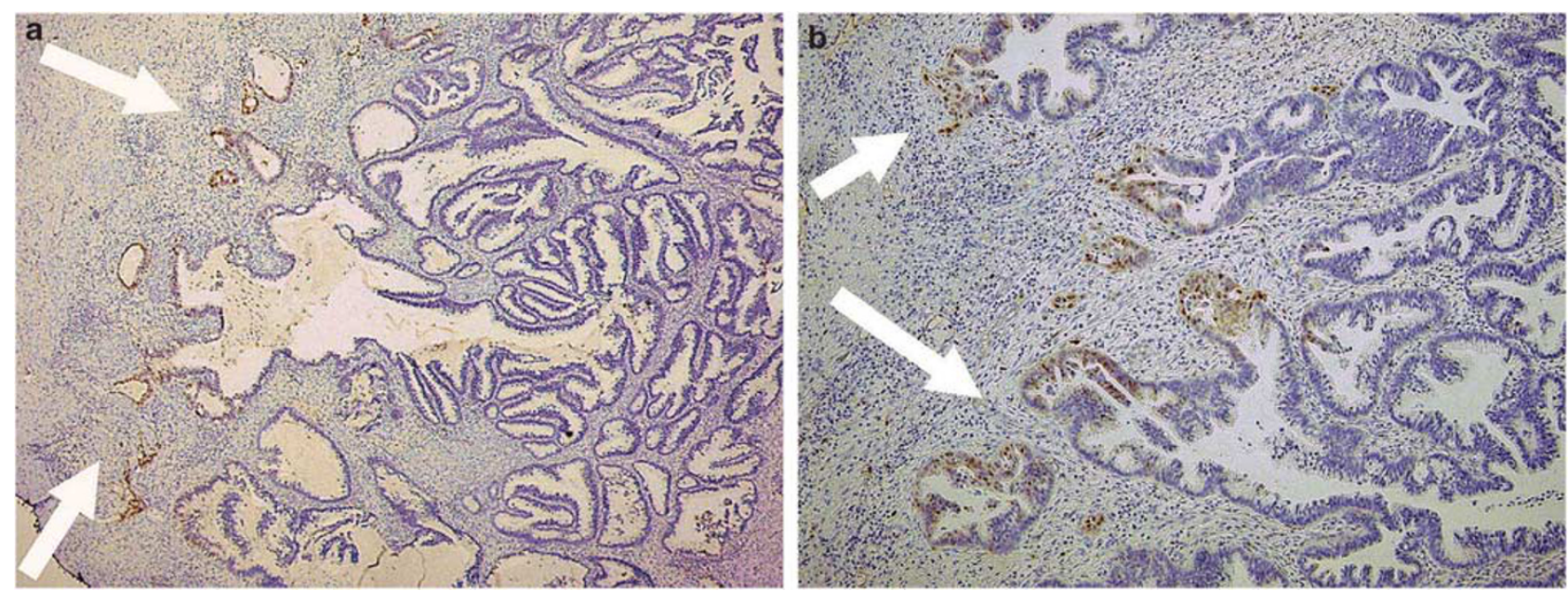

Figure 5 (a and b) Invasive adenocarcinoma showing cyclin D1 expression that is restricted to cells along the deep tumor margin (left field). Most of the invasive glands are negative.

normal or reactive glandular elements (Figure 1). Very focal ( $<10 \%$ of cells) cyclin D1 expression was present in five of the adenocarcinoma in situ cases, and the staining usually was associated with a morphological alteration in the neoplastic epithelium including cytomegaly, cytoplasmic eosinophilia, and increased nuclear pleomorphism (Figure 4). Some positive cells exhibited both nuclear and cytoplasmic cyclin D1 expression.

The invasive endocervical adenocarcinomas generally showed a similar immunophenotype to that of adenocarcinoma in situ. However, although most of the invasive glands were completely unstained, focal nuclear and cytoplasmic cyclin D1 expression was present in 10 tumors all of which were moderately differentiated. In these cases, $<10 \%$ of the tumor overall was positive and the staining was not randomly distributed but was mainly evident along the advancing tumor margin, typically at the deep aspect of the larger neoplastic glands (Figure 5). Cyclin D1 expression was also present within smaller glands and detached or discontinuous cell clusters within the stroma, and this staining pattern was focally seen around more superficial glands in some cases. The immunoreactive glands were often attenuated, lined by cells with more distinct eosinophilic cytoplasm, and were associated with a reactive and inflammatory stromal alteration (Figure 6). Cyclin D1 expression was also noted within endothelial cells and occasional inflammatory cells.

\section{Discussion}

Many tumors exhibit abnormalities within the RBp16-cyclin D1 pathways and in general these lead to up-regulation (or reduced degradation) of cyclin D1 

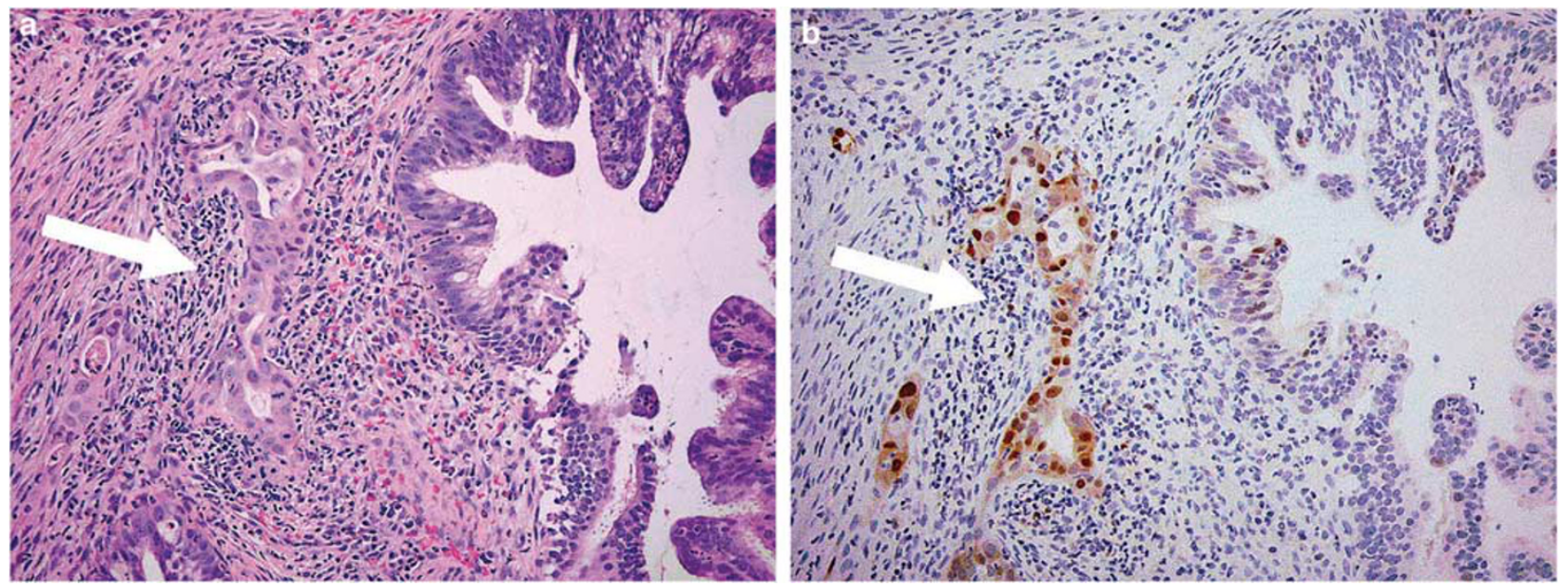

Figure 6 (a and b) Invasive adenocarcinoma showing nuclear and cytoplasmic cyclin D1 staining within smaller elongated glands lined by cells with eosinophilic cytoplasm (arrow). Most cells in the large invasive gland (right field) are negative.

and hence uncontrolled cellular proliferation, one of the hallmarks of neoplastic cells. Cyclin D1 also exhibits CDK-independent activities that influence apoptotic pathways, cellular migration, and angiogenesis all of which may be important in the neoplastic context. ${ }^{10-12,16}$ Over-expression of cyclin D1 has been documented in diverse neoplasms including breast carcinoma, head and neck squamous carcinoma, parathyroid adenoma and mantle cell lymphoma, and some studies have shown a correlation between increased cyclin D1 and adverse prognosis. Therefore, our observation that cyclin D1 immunoreactivity was usually lost in neoplastic endocervical lesions seemed to be a counter-intuitive finding, particularly as such lesions are known to show prominent mitotic activity. It also raised the possibility that (loss of) cyclin D1 expression might be a useful additional marker in the histological assessment of glandular lesions of the cervix as these frequently present difficulties in diagnosis.

This study confirmed our preliminary impression that neoplastic endocervical lesions generally did not show cyclin D1 immunoreactivity, whereas normal endocervical epithelium was usually positive, albeit with focal expression. The latter finding was consistent with the limited observations in earlier studies that have focused mainly on cervical squamous abnormalities. ${ }^{17,18}$ We also found that most stratified mucin-producing intraepithelial and high-grade CIN lesions were completely negative for cyclin D1, whereas normal squamous epithelium showed consistent parabasal reactivity. Earlier immunohistological studies of squamous lesions have shown conflicting results, some authors reporting absent or reduced staining compared with normal epithelium similar to our findings, ${ }^{17-22}$ whereas others have recorded increased cyclin D1 expression, particularly in high-grade CIN or squamous carcinoma. ${ }^{23-25}$ The reasons for these discrepancies are not entirely clear although variations in immunohistochemical techniques and interpretation of staining results may be relevant. ${ }^{26}$ It is also notable that some investigations have shown increased cyclin D1 mRNA in a proportion of intraepithelial or invasive cervical neoplasms in the absence of protein expression, suggesting that posttranscriptional mechanisms such as protein degradation may be important in some cases. ${ }^{18,27}$ Nevertheless, it seems that decreased cyclin D1 expression is a common event in cervical neoplastic lesions of both squamous and glandular subtype. The mechanism is most likely related to HPV infection, which has well-established associations with cervical neoplasia. The viral oncoprotein E7 binds to and inhibits the function of the RB protein which in effect bypasses the normal requirement for cyclin D1-CDK in the initiation of cell cycle entry. ${ }^{18,28}$ However, as RB is inactivated by HPV, there is a loss of the positive feedback loop and, therefore, downregulation of cyclin D1 despite the concurrent increase in cellular proliferation. Conversely, viral inactivation of the $\mathrm{RB}$ protein disrupts the negative feedback loop that normally inhibits p16 protein expression, and hence there is up-regulation of the latter protein even though it is functionally inactive. This explains the apparently paradoxical (but diagnostically useful) increase in a tumor suppressor protein (p16), and complementary decrease in a proliferation-associated mediator (cyclin D1), in neoplastic cervical lesions. Similar findings have been reported in squamous carcinoma of the head and neck, particularly tonsillar carcinoma, where loss of cyclin D1 expression and up-regulation of p16 protein are closely correlated with HPV positivity. ${ }^{29,30}$

Regarding the potential utility of cyclin D1 in diagnostic settings, it should be noted that the staining pattern in normal endocervical epithelium was seldom uniform. However, completely negative glands were seldom observed and cyclin 
D1 expression was generally increased in reactive glandular cells including foci of tuboendometrioid metaplasia that are more likely to create diagnostic difficulty and confusion with adenocarcinoma in situ. Microglandular hyperplasia and mesonephric duct elements were also cyclin D1 positive although relatively few cases were examined in this study. Therefore, cyclin D1 would seem to be a useful additional immunohistochemical marker in the assessment of problematic endocervical glandular lesions. Our study also confirmed the value of p16 protein, Ki-67, and bcl-2 in this diagnostic setting but each of these antibodies showed previously described limitations, for example, the frequent and occasionally diffuse expression of p16 protein in reactive endocervical cells and in tubo-endometrioid metaplasia. ${ }^{31}$ These findings again emphasize the value of immunohistochemical panels in problematic diagnostic cases as any single antibody may provide misleading results on occasion.

Although most cases of adenocarcinoma in situ showed complete loss of cyclin D1 expression, focal staining $(<10 \%$ of cells) was observed in five cases. Interestingly, such staining was frequently associated with a cytological alteration in the neoplastic epithelium including more marked nuclear atypia and cytoplasmic eosinophilia compared with the adjacent unstained 'conventional' appearing adenocarcinoma in situ. The morphological features precluded any confusion with a reactive process and, therefore, did not diminish the diagnostic value of cyclin D1 staining in these cases. The similarities between these cytological changes and those described earlier in superficially invasive cervical adenocarcinomas raise the possibility that they could indicate an increased or incipient invasive potential within the in situ lesions. ${ }^{32}$ However, further studies would be required to confirm this hypothesis.

The endocervical adenocarcinomas in this study showed a distinct pattern of cyclin D1 expression. Although most invasive glands were completely unstained, similar to the findings in adenocarcinoma in situ, focal immunoreactivity was observed in 10 cases and was largely restricted to the deep advancing margin of these tumors. This specific distribution pattern suggests a localized alteration in cell cycle regulation at the tumorstromal interface, which may be relevant to the invasive process. It is known that cyclin D1 has functions other than those related directly to cellular proliferation including influences on cellular adhesion and migration. ${ }^{16}$ Further studies are required to determine the significance of focal cyclin D1 expression in cervical adenocarcinoma but the present findings further illustrate the importance of considering microanatomical variations in staining patterns, even if these are restricted to a minority of cells, as they may be relevant to tumor progression. ${ }^{33,34}$

\section{Disclosure/conflict of interest}

The authors declare no conflict of interest.

\section{References}

1 Schorge JO, Knowles LM, Lea JS. Adenocarcinoma of the cervix. Curr Treat Options Oncol 2004;5:119-127.

2 Bray $\mathrm{F}$, Carstensen B, Moller $\mathrm{H}$, et al. Incidence trends of adenocarcinoma of the cervix in 13 European countries. Cancer Epidemiol Biomarkers Prev 2005;14: 2191-2199.

3 Sasieni P, Castanon A, Cuzick J. Screening and adenocarcinoma of the cervix. Int J Cancer 2009;125: $525-529$.

4 Lindeque BG. Management of cervical premalignant lesions. Best Pract Res Clin Obstet Gynaecol 2005;19: $545-561$.

5 Zaino RJ. Symposium part I: adenocarcinoma in situ, glandular dysplasia, and early invasive adenocarcinoma of the uterine cervix. Int J Gynecol Pathol 2002;21: 314-326.

6 Young RH, Clement PB. Pseudoneoplastic glandular lesions of the uterine cervix. Semin Diagn Pathol 1991; 8:234-249.

7 Nucci MR. Symposium part III: tumor-like glandular lesions of the uterine cervix. Int J Gynecol Pathol 2002; 21:347-359.

8 McCluggage WG. Immunohistochemistry as a diagnostic aid in cervical pathology. Pathology 2007;39 :97-111.

9 Park KJ, Soslow RA. Current concepts in cervical pathology. Arch Pathol Lab Med 2009;133:729-738.

10 Donnellan R, Chetty R. Cyclin D1 and human neoplasia. J Clin Pathol Mol Pathol 1998;51:1-7.

$11 \mathrm{Fu} \mathrm{M}$, Wang C, Li Z, et al. Minireview: cyclin D1: normal and abnormal functions. Endocrinol 2004;145: 5439-5447.

12 Kim JK, Diehl JA. Nuclear cyclin D1: an oncogenic driver in human cancer. J Cell Physiol 2009;220: 292-296.

13 Sherr CJ. The INK4a/ARF network in tumour suppression. Nature Rev Mol Cell Biol 2001;2:731-737.

14 Park JJ, Sun D, Quade BJ, et al. Stratified mucinproducing intraepithelial lesions of the cervix: adenosquamous or columnar cell neoplasia? Am J Surg Pathol 2000;24:1414-1419.

15 Young RH, Clement PB. Endocervical adenocarcinoma and its variants: their morphology and differential diagnosis. Histopathology 2002;41:185-207.

$16 \mathrm{Li} \mathrm{Z,} \mathrm{Wang} \mathrm{C,} \mathrm{Prendergast} \mathrm{GC,} \mathrm{et} \mathrm{al.} \mathrm{Cyclin} \mathrm{D1}$ functions in cell migration. Cell Cycle 2006;5: 2440-2442.

17 Cho NH, Kim YT, Kim JW. Correlation between G1 cyclins and HPV in the uterine cervix. Int J Gynecol Pathol 1997;16:339-347.

18 Nichols GE, Williams ME, Gaffey MJ, et al. Cyclin D1 gene expression in human cervical neoplasia. Mod Pathol 1996;9:418-425.

19 Schorge JO, Lea JS, Elias KJ, et al. P16 as a molecular biomarker of cervical adenocarcinoma. Am J Obstet Gynecol 2004;190:668-673.

20 Bae D-S, Cho S-B, Kim Y-J, et al. Aberrant expression of cyclin D1 is associated with poor prognosis in early 
stage cervical cancer of the uterus. Gynecol Oncol 2001;81:341-347.

21 Vijayalakshmi N, Selvaluxmi G, Majhi U, et al. Alterations found in $\mathrm{p} 16 / \mathrm{Rb} /$ cyclin D1 pathway in the dysplastic and malignant cervical epithelium. Oncol Res 2007;16:527-533.

22 Queiroz C, Silva TC, Alves VAF, et al. Comparative study of the expression of cellular proteins in cervical intraepithelial lesions. Pathol Res Pract 2006;202: 731-737.

23 Bahnassy AA, Zekri ARN, Saleh M, et al. The possible role of cell cycle regulators in multistep process of HPV-associated cervical carcinoma. BMC Clin Pathol 2007;7:4.

24 Cheung TH, Yu MM, Lo KW, et al. Alteration of cyclin D1 and CDK4 gene in carcinoma of uterine cervix. Cancer Lett 2001;166:199-206.

25 Conesa-Zamora P, Domenech-Peris A, Orantes-Casado FJ, et al. Effect of human papillomavirus on cell cyclerelated proteins p16, Ki-67, cyclin D1, p53, and ProEx $\mathrm{C}$ in precursor lesions of cervical carcinoma: a tissue microarray study. Am J Clin Pathol 2009;132:378-390.

26 Kim YT, Zhao M. Aberrant cell cycle regulation in cervical carcinoma. Yonsei Med J 2005;46:597-613.

27 Skomedal H, Forus A, Holm R. Deregulation of D-type cyclins in uterine cancers. Cyclin D1/D3 is differentially expressed in cervical cancer. Anticancer Res 2003;23(5A):3929-3935.
28 Skomedal H, Kristensen GB, Lie AK, et al. Aberrant expression of the cell cycle associated proteins TP53, MDM2, p21, p27, cdk4, cyclin D1, RB, and EGFR in cervical carcinomas. Gynecol Oncol 1999;73:223-228.

$29 \mathrm{Li} \mathrm{W}$, Thompson CH, Cossart YE, et al. The expression of key cell cycle markers and presence of human papillomavirus in squamous cell carcinoma of the tonsil. Head Neck 2004;26:1-9.

30 Andl T, Khan T, Pfuhl A, et al. Etiological involvement of oncogenic human papillomavirus in tonsillar squamous cell carcinomas lacking retinoblastoma cell cycle control. Cancer Res 1998;58:5-13.

31 Mulvaney NJ, Allen DG, Wilson SM. Diagnostic utility of p16INK4a: a reappraisal of its use in cervical biopsies. Pathology 2008;40:335-344.

32 Rollason TP, Cullimore J, Bradgate MG. A suggested columnar cell morphological equivalent of squamous carcinoma in situ with early stromal invasion. Int J Gynecol Pathol 1989;8:230-236.

33 Stewart CJR, Little L. Immunophenotypic features of MELF pattern invasion in endometrial adenocarcinoma: evidence for epithelial-mesenchymal transition. Histopathology 2009;55:91-101.

34 Stewart CJR, Crook ML, Leung YC, et al. Expression of cell cycle regulatory proteins in endometrial adenocarcinoma: variations in conventional tumor areas and in microcystic, elongated and fragmented glands. Mod Pathol 2009;22:725-733. 